\section{Panorama do Uso de Games, Serious Games e Gamificação na Educạ̧ão}

\section{Resumo}

O uso de games, serious games e gamificação, tanto no Ensino Básico quanto no Superior, vem sendo utilizado cada vez com maior frequência. O presente estudo tem como objetivo apresentar um panorama de como eles vêm sendo utilizados nestas esferas educacionais, com bases em evidências científicas. Ao final, são realizadas considerações acerca das limitações e sugestões para futuros estudos.

Palavras-chave: gamificação, games, serious games, educação, aprendizagem.

\section{Introdução}

O jogo sempre fez parte da vida do ser humano como elemento cultural (HUIZINGA, 2001) e, por muitos séculos, tem nos proporcionado prazer e diversão (SAILER et al., 2017). Mais recentemente, tem se utilizado as suas propriedades motivacionais para fins educacionais (GARRIS; AHLERS; DRISKELL, 2002; VAN, 2006; GEE, 2003).

Um dos grandes desafios da atualidade é engajar o aluno no processo de aprendizagem, aproximar da realidade tornando o aprendizado mais atrativo e desenvolver habilidades (VIEIRA et al., 2018; CHIN LU; LI JENG, 2013; GORBANEV et al., 2018). Os jogos também podem proporcionam a experiência de flow descrita por Csikszentmihalyi (1990), uma sensação de prazer e controle, onde as habilidades de um indivíduo são compatíveis com os ótimos desafios enfrentados promovendo motivação intrínseca uma vez que a satisfação experienciada é inerente a tarefa em si executado por si mesmo. Outra característica importante deste estado da motivação intrínseca e a perda da noção do tempo e do self (GARRIS; AHLERS; DRISKELL, 2002; DOMENICO; RYAN, 2017).

Existem várias formas de jogos que vêm sendo utilizados na educação. Os games são atividades voluntárias, regida por regras,
Prof. ${ }^{a}$ Dr. ${ }^{a}$ Camila Campanha

Doutora e Mestre pelo Programa de Pós-Graduação em

Distúrbios do Desenvolvimento da Universidade Presbiteriana Mackenzie no Laboratório de Neurociência Cognitiva e Social da Universidade Presbiteriana Mackenzie. Estágio de Doutorado no Neuromodulation Laboratory/ Spaulding Rehabilitation Hospital na Harvard Medical School. Especialista em Neuropsicologia. Psicóloga pela Universidade Presbiteriana Mackenzie. Professora e supervisora clínica do curso de Psicologia da Universidade Cruzeiro do Sul e professora convidada no curso de Pós-Graduação em Neurociência e Psicologia Aplicada da Universidade Presbiteriana Mackenzie. Colaboradora do Grupo Economia

Comportamental.org. Experiência com novas tecnologias como eletroencefalografia de alta densidade e técnicas de neuromodulação. Pesquisa sobre tomada de decisão social, de risco, neuroeconomia, confiança, cognição social, neurociência organizacional.

\section{E-mail: camila.campanha@ cruzeirodosul.edu.br}

\section{Prof. ${ }^{a}$ Dr. ${ }^{a}$ Ana Paula Soares de Campos}

Doutoranda e Mestre pelo Programa de Pós-Graduação em Distúrbios do Desenvolvimento na Universidade Presbiteriana Mackenzie. Atualmente é professora da Universidade Presbiteriana Mackenzie no curso de pós-graduação em Psicopedagogia, nos cursos de Pedagogia, licenciaturas presenciais e na Educação a Distância (EAD).

E-mail: anapaulasdec@ gmail.com 
agradável e separada do mundo real, improdutiva no sentido de não produzir bens de valor e incerta (CAILLOIS, 1961 apud GARRIS; AHLERS; DRISKELL, 2002). Entretanto, o uso de games na educação visa utilizar as características dos games para ensinar conceitos básicos e habilidades que podem ser por meio dos serious games ou gamificação. Serious games (jogo sério em tradução livre), é definido como games com propósito pedagógico (GORBANEV et al., 2018) que apresenta nove características - Controle, Ambiente, Linguagem de Ação, Avaliação, Ficção, Conflito/Desafio, Regras/Metas, Interação Humana e Imersão (BEDWELL et al., 2012). Já a gamificação tem sido definida como o uso de elementos de design de games em contexto de não-games (DETERDING et al., 2011), com o objetivo de aprendizagem visando criar experiência de imersão de forma similar aos experienciados nos games (CODISH \& RAVID, 2015).

Inúmeros estudos têm investigado o potencial dos games comerciais, serious games e gamificação tanto na educação básica quanto no Ensino Superior buscando verificar grau de eficácia na aprendizagem de conceitos básicos e desenvolvimento de habilidades específicas, satisfação do usuário, mudança no desempenho acadêmico, entre outras variáveis, como estratégias complementares ao ensino tradicional.

O ensino tradicional é baseado na transmissão de informações e memorização destes quase como forma de palestras. Já os jogos oferecem ao aluno um engajamento maior ao confrontá-lo com um problema envolvente e oferece maneiras diferente possíveis de resolvê-lo (GORBANEV et al., 2018; GALUP et al., 2015; PUTZ et al., 2018; TRIVIÑO-CABRERA et al., 2017; OLIVEIRA et al., 2017; HWANG; CHIU; CHEN, 2015).

Dessa forma, o presente estudo tem como objetivo apresentar um panorama dos games, serious games e gamificações que vem sendo utilizada na educação básica e no Ensino Superior com bases em evidências científicas. Não há pretensão em esgotar as possibilidades, mas sim apontar as possibilidades, formas de uso (estratégias pedagógicas) vêm sendo apontadas no aumento do engajamento do aluno, na facilitação da aprendizagem, desenvolvimento e treinamento de habilidades. No final, considerações são apresentadas em face das evidências e das limitações dos estudos, bem como sugestões para futuros estudos.

\section{Games, serious gamese gamificação na Educação Básica}

Na Educação Básica o professor está à frente do desafio de elaborar constantemente novas abordagens de ensino, com a preocupação em buscar métodos eficazes para atingir o objetivo de mediar o conhecimento aos seus alunos, procurando novas formas para possibilitar o aprendizado de maneira competente e que possam colocar em prática o que aprenderam.

Pensando sob essa ótica, a gamificação vem como uma forma de instrumentalizar e possibilitar novas estratégias (LEE; DOHN, 2012) para que os alunos possam aprender novas informações e competências através do uso da problematização como principal ferramenta (ROBINSON; ARONICA, 2019; SANTOS; FREITAS, 2017).

No ensino dos conteúdos que muitas vezes para os alunos é desmotivador ou até mesmo mecânico, a gamificação permite aproximá-los do conhecimento, possibilitando um comprometimento, produzindo uma ação frente ao conhecimento, impulsionando a aprendizagem, definindo e resolvendo os problemas que estarão expostos durante o seu período escolar. A grande tendência desta estratégia para a educação é inspirar, cativar e instigar pessoas (KAPP, 2012).

Uma das principais críticas dos professores em relação ao seu trabalho frente aos alunos é o desafio de ensinar e manter os alunos engajados e comprometidos com as atividades propostas, promovendo atividades que despertem o interesse destes. Um estudo realizado pelo Ministério da Educação (MEC) em 2013 com alunos entre 15 a 17 anos para entender a desmotivação frente às propostas 
feitas pelos professores em sala de aula, entre outras questões que são vivenciadas no espaço escolar, verificou que, na opinião destes alunos, as disciplinas de língua portuguesa $(78,8 \%)$ e matemática $(77,65)$ apresentam uma utilidade maior em comparação as disciplinas de física, biologia, geografia e história (36\%).

Infelizmente a escola tem mostrado dificuldades de apresentar para o aluno as reais necessidades de aprender determinados conteúdos para que, futuramente, ele possa usufruir e colocar em prática o que aprendeu. A partir deste ponto de análise, a gamificação vem de encontro a este desafio, uma vez que permite a melhora no engajamento dos alunos quando utilizam estes tipos de ferramentas. Os resultados em relação à aprendizagem em diversas áreas apresentam eficiência e o objetivo da aprendizagem é alcançado (NETO; SILVA; BITTENCOURT, 2015).

A utilização da Digital Game-Based Learning (DBGL) compreendida como a aprendizagem em jogos, ou seja, o uso de elementos do videogame na proposta de ensino e aprendizagem do professor em sala de aula, permite novas estratégias de aprendizagem. Propõe três estratégias diferentes: a elaboração e o design dos jogos para o uso educacional (serious games), o uso do videogame comercial para ocasiões específicas dentro do processo que o professor atua com aluno e a criação dos jogos feitos pelos próprios alunos (VAN, 2006).

A partir deste pressuposto que a ferramenta gamificação pode se ocupar do espaço do "design", entende-se que é uma estratégia para a interlocução entre o game e a aprendizagem, entendido que uma boa proposta, ou seja, um bom game permitirá uma experiência adequada e eficiente de aprendizagem e possibilitando o levantamento de estratégias para a melhor resolução de problemas enfrentados pelos alunos da Educação Básica nas mais variadas situações (GEE, 2003).

A gamificação tem se expandido para o uso na Educação Básica. Um estudo feito por Araújo, Silva e Lima (2016), através de uma revisão sistemática da literatura, investigaram o uso dos games na educação e buscaram levantar que tipos de questionamentos e estratégias estão sendo aplicados na educação. Dos 634 artigos analisados, foram incluídos apenas 13 através de critérios específicos de inclusão e chegaram ao número de $23 \%$ dos artigos apresentavam propostas para o Ensino Fundamental I, 39\% no Ensino Fundamental II, o demais compreenderam propostas para a educação no Ensino Superior.

Existiu uma correlação positiva para a maioria dos jogos criados, ocorrendo a relação conteúdos e games que estavam sendo trabalhados. Os autores concluem que há uma variedade nas propostas que estão utilizando para desenvolver os games e é possível mensurar vantagens importantes para a aprendizagem.

A seguir serão destacadas algumas pesquisas com evidências científicas sobre o uso da gamificação na Educação Básica nos seus vários ciclos.

\section{Educação Infantil}

Oliveira (2017) desenvolveu um aplicativo que pode ser usando em smartphones ou tablets na plataforma Android para auxiliar as crianças na idade de alfabetização. O jogo é inspirado no jogo chamado "forca" tradicional seguindo a mesma regra: o jogador opta pelas letras do alfabeto que julga formar a palavra que está oculta apenas limitada pela quantidade de linhas, caso o jogador mencione letras que não façam parte da escrita da palavra, aparecerão partes do corpo do personagem proposto pelo jogo.

Durante a jogada, o jogador terá apenas 6 tentativas, caso ele não consiga, o seu personagem será "enforcado" e assim, perderá a jogada. O jogo é organizado em rodadas, e em cada uma são apresentados cinco desafios diferentes e, ao final de cada rodada, o aluno tem um retorno do seu desempenho, aparecendo frases de incentivo e encorajamento. O jogador poderá optar pelos temas e níveis de dificuldade que queira fazer, e é possível personalizar os temas tanto pelo professor quantos pelos responsáveis da criança que estiverem utilizando o jogo, podendo, assim, colocar opções relacionadas aos assuntos 
desenvolvidos pelo professor em sala de aula. $O$ aplicativo $A B C$ da Forca está na Play Store com acesso apenas para Android (Figura 1).

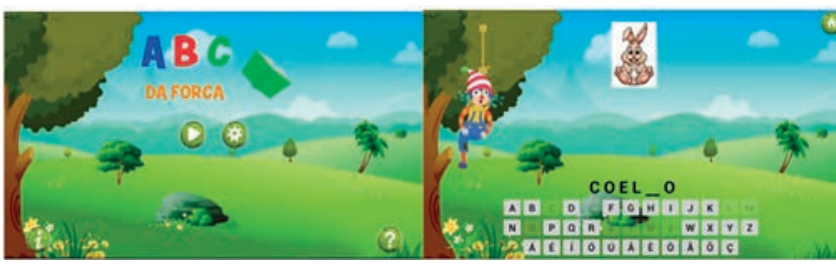

Figura 1 - Exemplo da tela do jogo "ABC da forca"

Fonte: Repositório UFPB

O aplicativo obteve um retorno positivo tanto dos professores quanto das famílias, pela fácil aplicação e a possibilidade de personalizar as atividades. Os aspectos que precisam ser revistos é a variabilidade nos desafios e alguns caminhos no uso serem mais fáceis pelo manuseio do jogador (OLIVEIRA, 2017).

Lima (2017) criou um aplicativo para desenvolver o raciocínio lógico das crianças associado à noção de programação computacional utilizando-se de atividades lúdicas. Foi utilizado o sistema operacional Android. A principal característica do aplicativo é a comunicação via bluetooth com um robô desenvolvido em Arduino, ou seja, um dispositivo robótico que entende as ordens feitas e as realiza. O jogo é composto por um tabuleiro, dividido por colunas e linhas, e uma marca que é demarcado o início de onde o ratinho precisa partir.

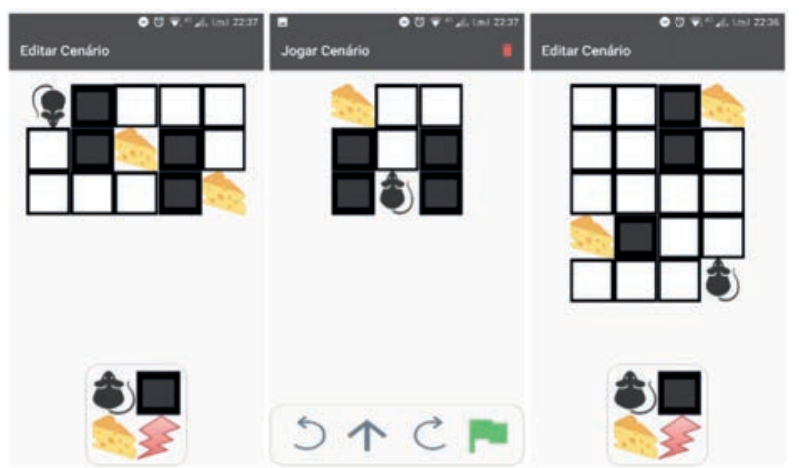

Figura 2 - Exemplos de telas do aplicativo Fonte: Repositório UCS

A parte final é representada pelo queijo. A quantidade de queijos e os obstáculos são propostos pela criança no momento da criação da atividade, e o objetivo é o ratinho comer todos os queijos que estiverem no tabuleiro passando pelos obstáculos (Figura 2).

A pesquisa contou com 18 crianças cursando o pré e o jardim. Foram divididas em grupos e apresentadas ao robô e ao aplicativo. As criancas passavam pelo experimento durante 20 minutos e houve envolvimento delas em todas as atividades propostas.

O autor concluiu que as habilidades de raciocínio lógico e pensamento computacional são imprescindíveis para o desenvolvimento infantil sendo preditoras para situações que elas vivenciarão nas fases seguintes como as funções executivas (controle inibitório, memória de trabalho, flexibilidade cognitiva, organização, atenção etc.).

Os problemas encontrados na pesquisa foram o não conhecimento e familiaridade dos professores com a proposta (linguagem computacional e de programação), a associação de temas entre o lúdico e o concreto e a falta de preparo estrutural da instituição de ensino (LIMA, 2017).

\section{Ensino Fundamental I}

A pesquisas de Chin Lu e Li Jeng (2013) relata sobre a eficácia do uso da ferramenta no processo de aprendizagem dos alunos num estudo feito na cidade de Taipé em Taiwan utilizando-se de um jogo (DGBI) para ensinar conceitos científicos sobre insetos baseado em um material didático. A pesquisa passou por duas fases: desenvolvimento e avaliação. $\mathrm{Na}$ fase de desenvolvimento foi para a criação do jogo baseado no material didático dos alunos e na fase de avaliação foi utilizado um questionário. Foi utilizado o método quase experimental, para poder garantir que o conteúdo estava adequado para as criancas e se era possivel de aprender com o jogo. Para garantir que as crianças aprendessem sobre o assunto proposto foi elaborado um questionário de 21 perguntas que intitularam como "teste de concepção cognitiva de insetos" que são divididos em: identificar os insetos, localizar a posição dos pés e asas dos 
insetos, sobre as bocas e hábitos alimentares dos insetos (Figura 3).
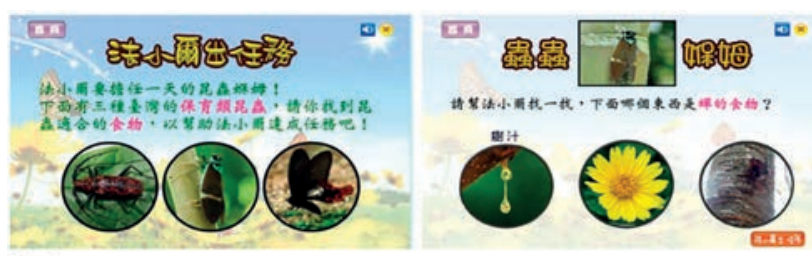

Figare 6
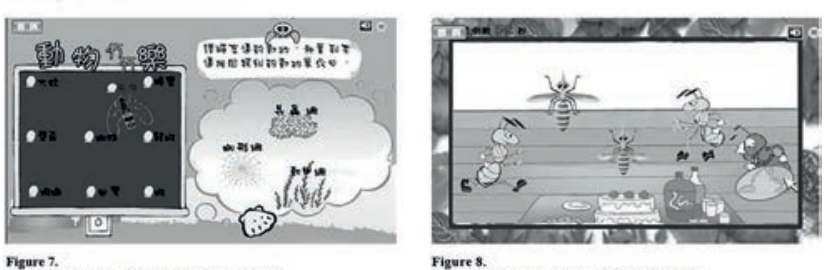

Figure 8.

Figure 7.
The inter:

Figura 3 - Exemplos de telas do game

Fonte: Scientific Research

Ao final da pesquisa os autores concluíram por meio das análises estatísticas que o jogo é eficaz na aprendizagem das crianças e houve envolvimento e motivação nas atividades que foram propostas. Com o questionário feito com os alunos foi possível observar que eles conseguiram uma melhor compreensão sobre os insetos, entendimento das relações de características físicas e hábitos alimentares. Um outro dado também é a possibilidade de os alunos aprenderem sozinhos, mas ainda faltam mais testes para confirmar este dado. Para alguns alunos o jogo pareceu um pouco difícil, é preciso avaliar ainda com mais precisão este dado se está relacionado com alunos com dificuldades de aprendizagem ou falta de conhecimentos prévios sobre o assunto (CHIN LU; LI JENG, 2013).

\section{Ensino Fundamental II e Ensino Médio}

Neste outro estudo Hwang, Chiu e Chen (2015) desenvolveram um jogo para trabalhar investigações dentro do contexto com as áreas de estudos sociais (história e geografia) na cidade de Taiwan. O objetivo é utilizar um game para a estimulação da aprendizagem frente aos conteúdos da área a ser desenvolvida. É inspirado nos jogos de RPG utilizando-se da tecnologia 2D, pensando na possibilidade de usar nos computadores que as escolas em Taiwan oferecem
(Figura 3). Participaram da pesquisa 87 alunos do sexto ano, idade de 12 anos divididos em grupo controle e experimental.

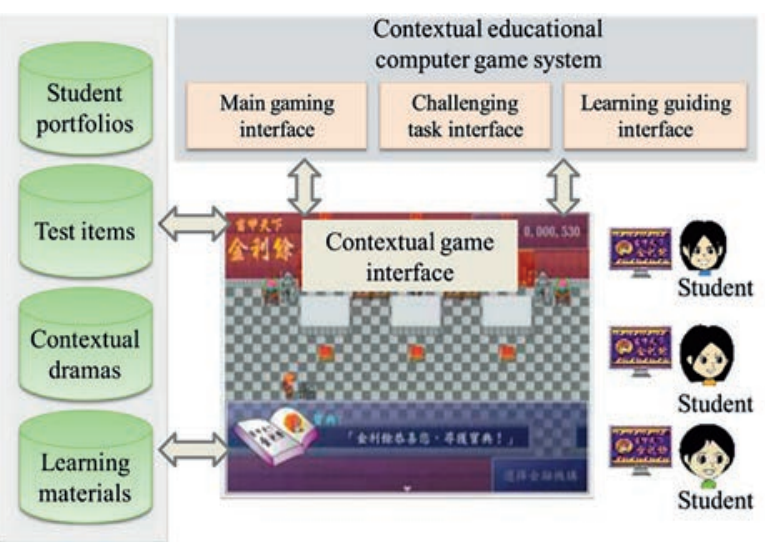

Figura 4 - Exemplo da estrutura do game de computador contextual educacional

Fonte: Science Direct

A pesquisa conseguiu atingir o objetivo de melhorar a aprendizagem dos alunos em relação aos conteúdos de estudos sociais, oferecendo outras formas de explorar os assuntos, ou seja, através dos games. Além disso, observaram aumento do flow, uma experiência de total absorção em uma atividade, não auto consciente que gera prazer e satisfação sendo auto reforçador, ou seja, a satisfação é inerente da atividade (DOMENICO; RYAN, 2017), no grupo experimental do que o grupo controle, apontando para um balanço ideal entre desafio do jogo e conhecimento dos estudantes. O formato de game pode ser usado em outros cenários e temas de aprendizagem, e de acordo com os pesquisadores, futuramente, será utilizado em outras áreas como ciências, matemática, idiomas etc (HWANG; CHIU; CHEN, 2015).

Delavalli e Corrêa (2014) criaram um aplicativo para aproximar alunos e professores dos estudos, trazendo maior engajamento dos alunos nesta difícil tarefa, fazer o aluno estudar e compreender a sua relevância. A ferramenta chamada EduChat permite uma melhor comunicação entre alunos e professores, através de bate-papo, postagens de materiais, áudios, vídeos e imagens, para auxiliar na exposição dos conteúdos trabalhados em sala. 

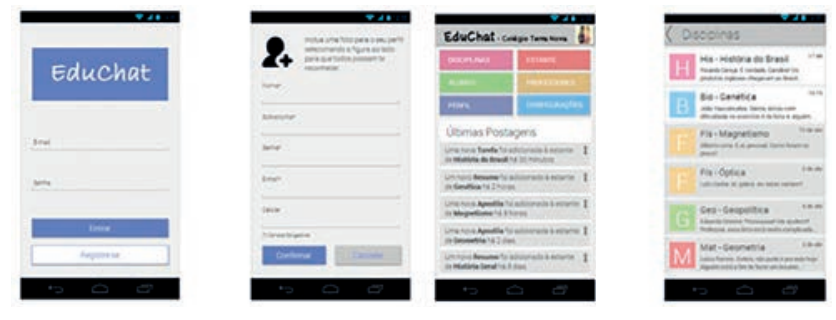

Figura 5 - Exemplos de telas do aplicativo

Fonte: BSI - Bacharelado em

Sistema de Informação

O principal objetivo do aplicativo é que seja uma comunicação mais rápida para resolver problemas com dúvidas, ideias que podem surgir entre os alunos, e a aproximação entre os alunos e alunos com os professores. Podem ter três tipos de usuários: diretor, professor e aluno. $O$ diretor que permitirá o uso do aplicativo na escola, sendo ele o responsável para fazer o download do aplicativo e cadastrar os professores para o uso da ferramenta. Depois do cadastramento, os professores colocarão os seus alunos no aplicativo, que também deverão fazer um cadastramento. Os alunos poderão acessar as disciplinas dos professores e interagir com os conteúdos propostos. O professor será o mediador, controlando os acessos, as conversas que são feitas na sua disciplina e as dúvidas que os alunos irão postando respondendo sempre que possível (Figura 5).

O uso do aplicativo na escola pode trazer muitas vantagens e como também algumas desvantagens que precisam ser levadas em consideracão, como por exemplo, combinar a quantidade horas que o professor irá se dedicar ao aplicativo, para não exceder ao que tem no contrato com a escola. É preciso acompanhar o desenvolvimento do aplicativo e o uso através de pesquisas feitas com o uso de questionários para verificar a satisfação e os problemas que podem surgir com o uso da ferramenta (DELAVALLI; CORRÊA, 2014).

Um outro exemplo no Brasil de um estudo feito na região nordeste com alunos de 11 a 14 anos para a estimulação do raciocínio lógico e pensamento computacional é o Kahoot (OLIVEIRA et al 2017). O objetivo é preparar os alunos para Olimpíada Brasileira de Informática (OPI) utilizando-se da ferramenta Kahoot que está disponível para Android e iOS. É um aplicativo gratuito com um formato de um quiz que pode ser usado para qualquer conteúdo de qualquer área do conhecimento, usado a partir da idade que os alunos estejam alfabetizados até a fase adulta. No aplicativo já existem alguns quiz prontos que podem ser acessados pelo usuário (Figura 6).

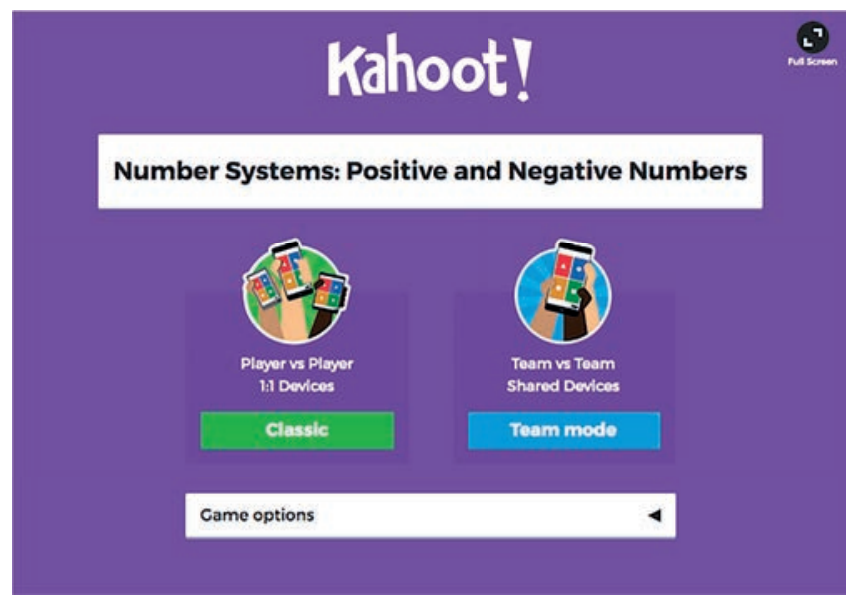

Figura 6 - Exemplo de tela do aplicativo

$$
\text { Fonte: Kahoot! }
$$

Foram feitos encontros semanais de $3 \mathrm{~h}$ no laboratório de informática, primeiramente a revisão do conteúdo teórico e logo após o uso da ferramenta Kahoot com o uso de 25 perguntas sobre o conteúdo trabalhado. Esta intervenção foi feita durante os meses de janeiro a novembro do mesmo ano. Os resultados foram positivos e ocorreu uma melhora adequada no processo de aprendizagem dos alunos, pois através de entrevistas com os alunos mencionaram que estavam mais instigados e comprometidos com o ensino e que estavam mais seguros em relação aos conteúdos aprendidos (OLIVEIRA, et al 2017).

Um outro exemplo no Brasil na região Norte uma pesquisa feita por Pantoja e Pereira (2018) numa escola pública com 4 salas do $6^{\circ}$ ano do Ensino Fundamental II utilizaram o aplicativo Duolingo para o ensino da língua inglesa. O aplicativo é gratuito e propõe o ensino de idiomas fazendo a combinação da gamificação com a praticidade de se estudar via smartphones ou tablets. $O$ aplicativo além de ensinar um novo idioma, também tem ferramentas para a tradução de documentos e sites. A cada atividade que o usuário vai concluindo de forma correta vai passando para as próximas aumentando a sua 
dificuldade, caso o usuário não consiga responder da forma correta, ele é instigado a refletir sobre o seu erro e tentar de novo (Figura 7).

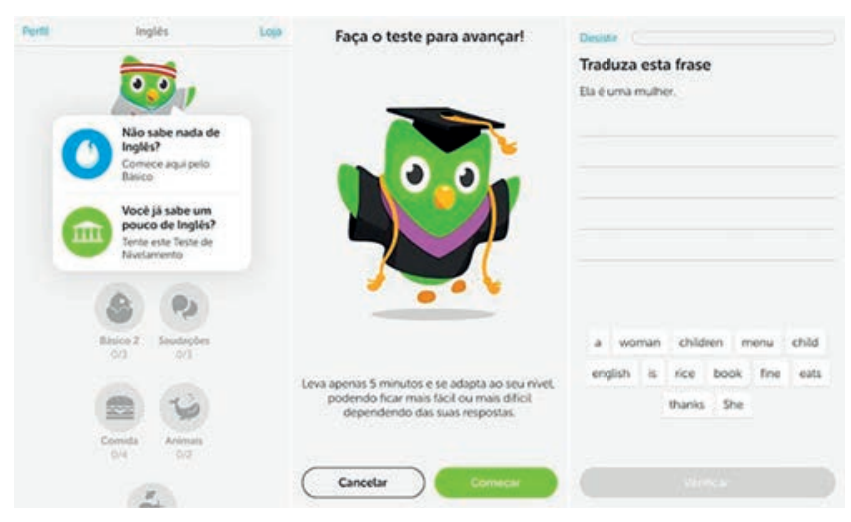

Figura 7 - Exemplo de tela do aplicativo Fonte: Techtudo

O estudo teve como objetivo verificar a eficácia do uso da ferramenta do ensino de um novo idioma comparando os resultados das salas de aula (controle) que utilizaram apenas o método tradicional de ensino de idiomas com a salas de aula (experimental) que utilizaram o aplicativo Duolingo, que permite o ensino de um idioma através da gamificação. Os autores concluíram no final do estudo que através do uso de avaliações o melhor desempenho foi das salas experimentais, e um dado relevante para se destacar é que as salas que mais deixaram perguntas em branco nas avaliações após a pesquisa foram os alunos do grupo controle (PANTOJA; PEREIRA, 2018).

Portanto, o jogo como estratégia de aprendizagem no âmbito escolar é um caminho de ideias para propostas didático-pedagógicas e de entretenimento para os alunos, pensando no processo de aprendizagem que cada um tem, e permitindo através dos resultados dos games uma avaliação qualitativa, tendo como ponto principal as habilidades necessárias para o uso nas atividades pedagógicas que os jogos propõem. Importante destacar que as ações dos professores frente aos seus alunos precisam estar engajadas na estimulação de competências e habilidades que estão intrinsicamente correlacionadas com a ajuda e solidariedade, pensando em valores que são indispensáveis a vida humana e social, assim não dando ênfase somente a rivalidade (MARTINS, GIRAFFA, 2015).

\section{Games, Serious Games e Gamificação no Ensino Superior}

O uso de games e gamificação no Ensino Superior tem visado desenvolver habilidades acadêmicas e práticas específicas (GORBANEV et al., 2018; TRIVIÑO-CABRERA et al., 2017; NICOLAIDOU et al., 2015; CHON et al., 2019; VLACHOPOULOS; MAKRI, 2017; STARK; POMPEI, 2010), como também o aumento a motivação e o engajamento dos estudantes de forma mais efetiva ao utilizar uma linguagem similar aos games e aproximar da realidade tornando o aprendizado mais atrativo (VIEIRA et al., 2018). Além disso, com o aumento da educação a distância, pensar em estratégias para treinar habilidades práticas são fundamentais (CHON et al., 2019).

Os estudos têm apontado benefícios no uso de games no processo de aprendizagem cognitivas, comportamentais e afetivas com efeitos positivos (VLACHOPOULOS; MAKRI, 2017). Apesar do aumento do uso de games e gamificação no Ensino Superior, em Portugal por exemplo, menos de $20 \%$ dos projetos das instituições de Ensino Superior utilizam games e gamificação (ALMEIDA; SIMÕES, 2019).

Em relação à visão dos professores e a experiência destes em desenvolver estratégias de gamificação em suas disciplinas, consideraram o processo valioso e os tornaram mais conscientes do conteúdo que desejavam destacar e dos valores. Contudo, também acharam difícil o processo de criação de gamificação e um processo muito demorado (HUNG et al., 2017).

Cursos de diversas áreas tem se utilizado de games, serious games e gamificação no Ensino Superior. Com o objetivo de apresentar alguns estudos baseados em evidências científicas no Ensino Superior, seguem exemplos do uso de games, serious games e gamificação em cursos da área da saúde, que, segundo a base PubMed, existem atualmente em torno de 429 artigos na área de medicina e relacionados, e em outros cursos como as engenharias e computação, cursos estes que mais utilizam games e gamificação no Ensino Superior. 


\section{Games, Serious Games e Gamificação na Áreas da Saúde}

Na área da saúde, especialmente na medicina, serious games e simulações com pacientes virtuais permitem os estudantes colocarem em prática o conhecimento adquirido de treinarem as habilidades procedurais ao entrarem em contato com as consequências imediatas de diferentes decisões sem colocar vidas reais de pacientes em algum grau de risco. Dessa forma, o aumento de estudos e desenvolvimento de serious games e simuladores de pacientes virtuais tem sido significativo por vir sendo apontados como ótimas estratégias para desenvolver e melhorar habilidades dos futuros profissionais e residentes, diminuindo os riscos de erros de diagnósticos e tratamento (CHON et al., 2019).

Chon e colaboradores (2019) testaram um serious game, o Emerge, para verificar os efeitos na motivação e na aprendizagem declarativa e procedural dos estudantes de medicina da Universidade de Colônia, Alemanha. O Emerge é um departamento de Emergência e Acidente virtual complexo computadorizado desenvolvido pela Faculdade de Medicina da Universidade de Göttineng em colaboração com o centro médico da Universidade de Hamburgo - Eppendorf e PatientZero Games $\mathrm{GmbH}^{\circledR}$. Desde 2016 o jogo foi implementado no currículo da Faculdade de Medicina da Universidade de Göttineng.

A diferença deste jogo é que permite aos alunos de medicina assumirem o papel de um médico assistente junto a um mentor digital que auxilia o aluno na simulação de situações de emergência em que deve diagnosticar o paciente, solicitar exames, testes diagnósticos, fazer perguntas para o paciente e tomar medidas terapêuticas ao tratar até dez pacientes simultaneamente. Os pacientes apresentam tanto efeitos colaterais das escolhas dos tratamentos quanto evolução do quadro, ou seja, apresentam consequências reais. Além disso, os estudantes recebem feedback digital do diagnóstico e tratamento utilizado. O game permite interação livre com desafios na avaliação da emergência e os procedimentos necessários coordenando tarefas simultaneamente em alta imersão (Figura 8) (CHON et al., 2019; MIDDEKE et al., 2018).

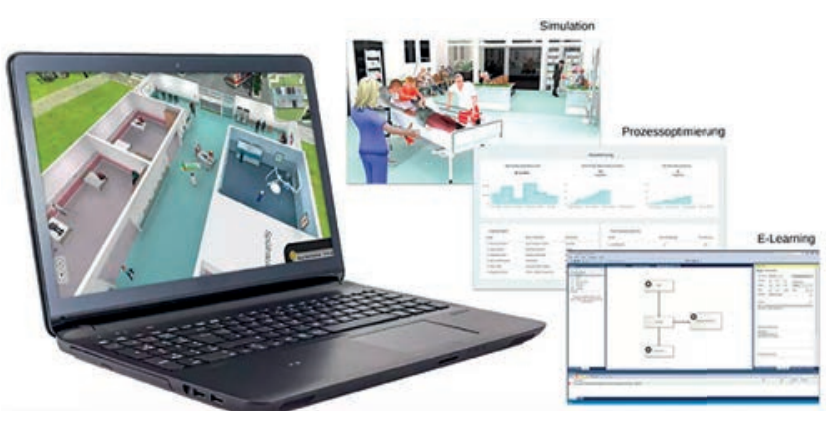

Figura 8 - Ilustração do serious game Emerge

Fonte: Pzg-testing

Chon e colaboradores (2019) convidaram 1.600 estudantes de Medicina da Universidade de Colônia do 50 ao 120 semestre. Um total de 140 estudantes de medicina aceitaram, sendo a maioria mulheres (96), na Alemanha, dois terços dos estudantes de medicina são mulheres. Neste estudo os autores criaram 4 casos clínicos com diferentes níveis de dificuldade: de pneumotórax, diverticulite sigmoide, isquemia mesentérica (fácil) e isquemia mesentérica (difícil). Como resultado nos testes pré e pós observaram um impacto positivo no conhecimento declarativo após o jogo no qual os estudantes pontuaram mais respostas corretas (média de 76, SD11,6 depois e média 60,4, SD 16.6 antes). Houve um ligeiro aumento na aprendizagem procedural. Além disso, escolheram o diagnóstico correto com maior frequência depois do jogo (33/740 23.6\% depois e $7 / 140,5 \%$ depois). Com relação à motivação os autores apontaram para uma limitação a ser considerada: dos 1.600 apenas 140 aceitaram participar do estudo, ou seja, estes já estariam motivados inicialmente em conhecer o jogo.

Contudo, o jogo foi amplamente aceito pelos estudantes e considerado divertido, o que aumenta a motivação. Outra limitação é o número de casos que os estudantes foram expostos, o não monitoramento dos ganhos ao longo prazo e o não controle de outras variáveis que podem ter contribuído para o melhor desempenho. Estudantes mais velhos obtiveram melhor desempenho. Tais considerações são importantes 
e precisam ser consideradas para futuros estudos avaliarem a eficácia do Emerge nos cursos de medicina. Entretanto, apresenta ser uma das ferramentas interessante no treinamento dos estudantes de medicina proporcionando uma experiência próxima da realidade sem os riscos de danos em pacientes reais.

Outro estudo interessante utilizou um serious game, o Telemedicina de Emergência Virtual, para a educação e treino de médicos e profissionais da saúde, em situações de complicações cardiovasculares e investigaram a percepção dos profissionais do potencial do jogo (NICOLAIDOU et al., 2015). O game é baseado em princípios de aprendizagem baseado em problemas, que promove a autoestimulação, contextualização envolvendo a aprendizagem ativa do aluno com uma abordagem prática empregando a gamificação. Devido à falta de games nesta linha na cardiologia, o game foi desenvolvido para sanar esta falta utilizando casos de pacientes em situações de emergência com problemas cardiovasculares. O game faz uso de dados de eletrocardiograma, reações do paciente em tempo real, com uma série de ferramentas disponíveis desde medicação, intervenções, conversar com o paciente, obtendo feedback e tempo real das ações do jogador (Figura 9). O game foi baseado em um sistema real desenvolvido pelos laboratórios de eHealth da Universidade de Chipre e Universidade de Frederick em parceria com a Stremble.
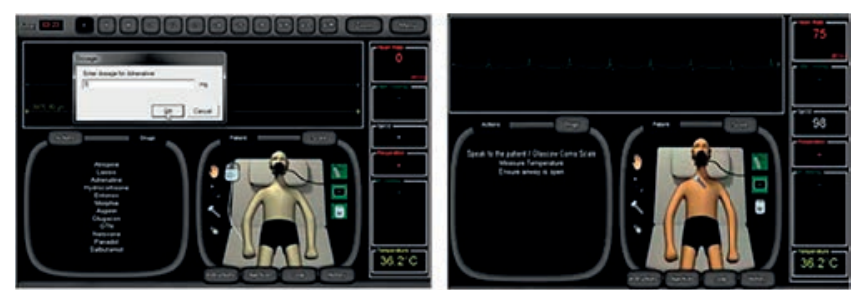

Figura 9 - Exemplos de tela do serious game Virtual Emergency TeleMedicine (VETM)

Fonte: Stremble

Neste estudo participaram 90 profissionais que trabalham em ambulâncias para avaliarem o game. Como resultado os autores observaram que os profissionais avaliaram de forma positiva todas as seis dimensões verificadas: interface do serious game, feedback, engajamento do usuário, nível de dificuldade e terminologia usada no jogo obtendo como média de 3,2 a 3,99 de 5 pontos nestas dimensões (NICOLAIDOU et al., 2015). Os autores concluem que o uso de elementos de jogo no treinamento do tratamento de complicações cardiovasculares tem um ótimo potencial de facilitar e engajar o participante no processo de aprendizagem. Um dos fatores contribuem ao aumento da motivação intrínseca para a prática tornando a experiência de aprendizagem mais agradável e mais efetiva (NICOLAIDOU et al., 2015).

Sites interativos utilizando gamificação e laboratórios virtuais são outras ferramentas interessantes para a aprendizagem. O site Learne Genetic da Universidade de Utah é um desses sites interativos muito interessante para ser utilizado no colégio, universidades e até pela população em geral. Segundo Stark e Pompei (2010), o objetivo da criação do site é de facilitar a compreensão sobre a genética e a genômica para que todos entendam. O site contém 8 tópicos que são subdivididos em 25 tópicos principais que são: Genética (Genética Básica, Criação de Pombos e o trabalho da genética, Epigenética e Ciência da Genética); Biologia Celular (Células Surpreendentes, Células Tronco e Clonagem); Plantas (Algodão e Comportamento dos Insetos \& Plantas); Ecologia (Microbioma Humano, Modelo da Terra, Astrobiologia e Ambientes Extremos - o grande lago salgado); Evolução (DNA e a Unidade da Vida); Saúde Humana (Metabolismo - da comida para o combustível, Medicina de Precisão, Desordens Genéticas, História da Saúde da Família e Terapia Genética); Neurociência (Neurociência Básica, Sistema Sensorial, Memória, Atenção, Distração e Adiç̧ão - Genética e o Cérebro); e Ferramentas da Ciência (Laboratórios Virtuais e Matemática). Cada tópico é abordado de forma clara e concisa, de forma interativa por meio de games, vídeos animados e de ação ao vivo, aplicativos, ilustrações e infográficos, páginas da web projetadas profissionalmente, atividades de aprendizagem não baseadas em impressão e outras não tecnológicas e guias de aula para educadores. Além disso, no tópico Ferramentas da Ciência contem quatro laboratório virtuais para 
os participantes explorarem. A equipe é comporta por professores e cientistas, além de educadores de ciências, designers instrucionais, escritores de ciências, professores de desenvolvedores profissionais, cientistas, designers de multimídia, desenvolvedores da Web e avaliadores (STARK e POMPEI, 2010).

Dentre as animações interativas, o "Mouse Party" (Festa dos Ratos em tradução livre) e o "Cell size and scale" (Tamanho e Escala da célula em tradução livre) são as mais acessadas e disseminadas do site gerando discussões sobre ciência em mais de 30 idiomas (STARK; POMPEI, 2010). O "Mouse Party", por exemplo, consiste em um aquário com ratos sob efeito de diferentes tipos de drogas com música de fundo. A seta do mouse se transforma na mão de um cientista com jaleco e luva de látex. Com essa mão o participante pode escolher e pegar um rato, colocá-lo em uma cadeira que o leva para dentro de uma máquina que mostra imagens de ação das drogas nas sinapses dos neurônios, os efeitos e quais áreas cerebrais são alteradas durante o efeito da droga (Figura 10). O tópico "The new science of addiction: Genetics and the brain" (A nova ciência da adição: Genética e o cérebro em tradução livre) foi o que está recebendo um uso imprevisto pelos autores: está sendo utilizado em treinamento de policiais e no tratamento de dependência química em vários países (STARK; POMPEI, 2010).
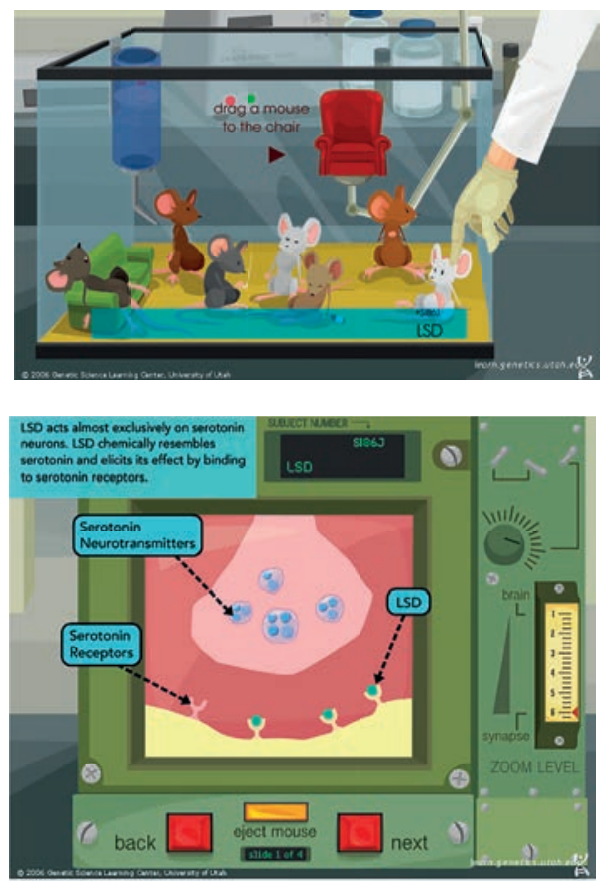

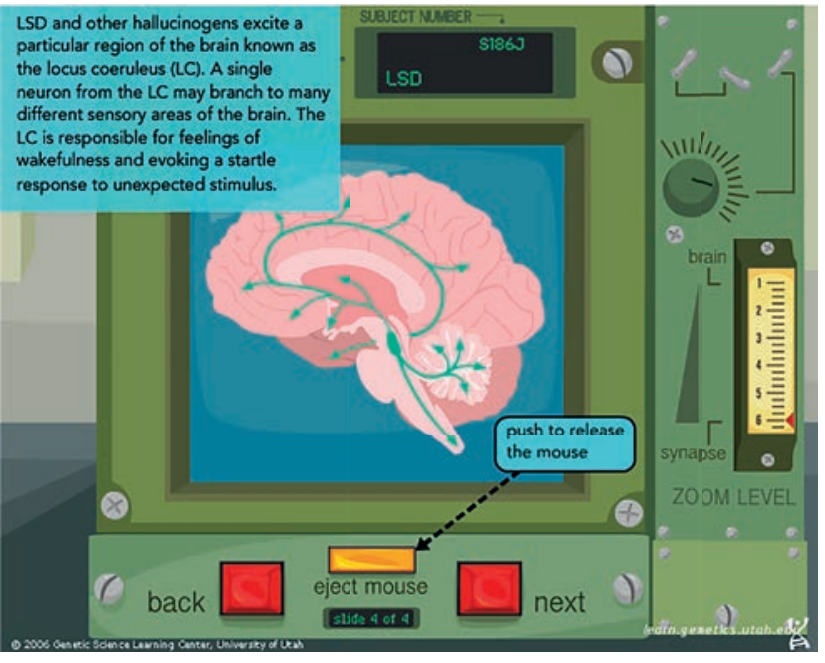

Figura 10 - Exemplos de como o Mouse Party apresenta o efeito das drogas no comportamento e no cérebro dos ratos

Fonte: Learn.Genetics

Com relação as atividades para educadores, estas foram desenvolvidas por vários profissionais e educadores para a sala de aula e foram projetadas para apoiar e ampliar os materiais do site, bem como outros recursos para eles. Estes recursos estão disponíveis no Teach Genetics, link que aparece em cada tópico com atividades voltadas para os tópicos (STARK; POMPEI, 2010). De acordo com Keiser (2010), o site contém uma riqueza muito grande de informações, atividades interativas e úteis, sendo de grande valor tanto para os professores do ensino médio quanto de Ensino Superior para poder ensinar os componentes genéticos em seus cursos. Stark e Pompei (2010), desenvolvem junto a sua equipe workshops de verão para elaborarem novas atividades para o site.

Além disso, o site apresenta aplicativos para iPhone e iPad (Apple Store) sobre percepção e sensação, sobre a genética dos pombos e um jogo que pode ser feito download sobre atenção e direção, todos são do tópico de Neurociência. Os autores também desenvolveram um aplicativo para cada sentido: visão, audição, tato, equilíbrio (propriocepção), paladar e olfato. No aplicativo da audição (Hear Neuroscience app), por exemplo, o usuário consegue ver como o ouvido interno processa diferentes frequências sonoras e pode até criar os seus próprios sons. Já o aplicativo sobre 
equilibrio (Balance Neuroscience) responde aos movimentos do usuário em tempo real, permitindo observar como o aparelho auditivo interno processa rotação, gravidade e aceleração (Figura 11).
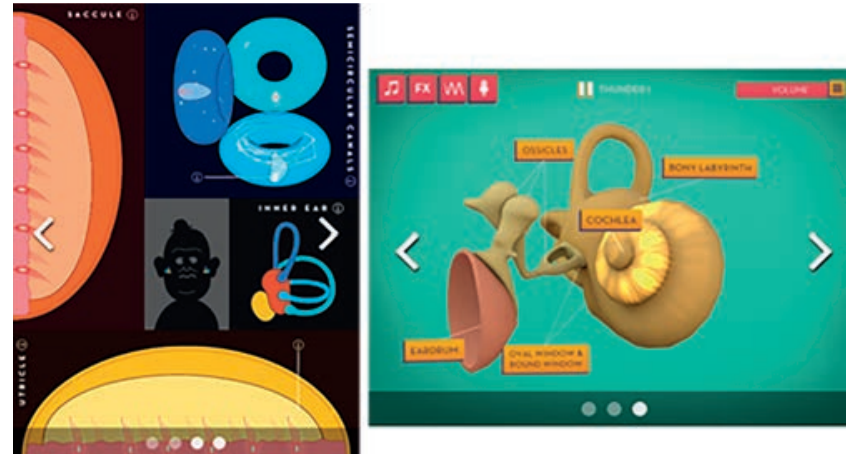

Figura 11 - Exemplos de telas do aplicativo Balance Neuroscience e do Hear Neuroscience

Fonte: Learn Genetics

O game sobre atenção e direção, Distractown, foi desenvolvido pelo Laboratório de Cognição Aplicada da Universidade de Utah (Figura 11). A ideia é mostrar como a distração cognitiva, como falar no celular, prejudica o desempenho ao dirigir. Neste jogo o participante precisa realizar uma tarefa de memorização de itens numéricos e recuperá-los na ordem correta ao mesmo tempo que executa resolução de problemas de matemática enquanto dirige. Watson e Strayer (2010) realizaram um estudo com esse jogo para verificar a interferência de duas tarefas complexas em 200 universitários voluntários (90 homens e 110 mulheres) nas versões computadorizadas e celular. Como resultados os autores observaram um decréscimo no desempenho da grande maioria dos jogadores nas tarefas. Contudo, apenas 2,5\% dos participantes apresentaram nenhum decréscimo de desempenho. Os autores chamaram estes participantes de supertaskers que apresentaram desempenho acima da média em todas as tarefas sendo acima do acaso, desempenho este acima de $97 \%$ da população que não consegue ter sem um grande custo de esforço (WATSON; STRAYER, 2010).

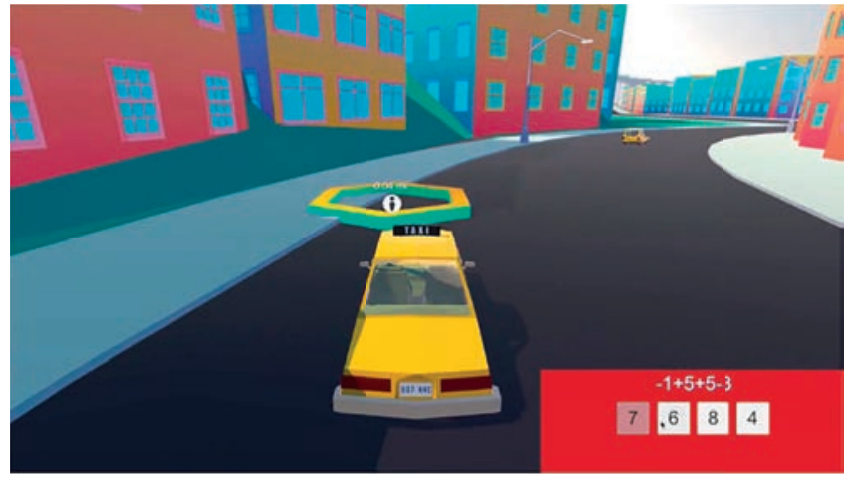

Figura 12 - Ilustração do game Distractown

Fonte: Learn Genetics

Em um artigo de revisão de estudos que utilizaram games digitais como forma de aprendizado na área da medicina, enfermagem, farmacologia e odontologia entre 2010 até 2015, foi observado pelos autores que os games podem ser considerados formas de aprimorar desempenho e aprendizado, promover o aprendizado individualizado, obtendo benefícios práticos e promovendo motivação para os alunos. Contudo, aspectos de logística na aplicação e barreiras no processo de ensino-aprendizagem são fatores desvantajosos no uso de games educativos (BIGDELI; KAUFMAN, 2017). Outra revisão sistemática do uso de serious games e gamificação na educação de profissionais da saúde buscou artigos de 1990 até 2017 para avaliar a efetividade destas metodologias. Como resultados os autores encontraram 27 artigos com ensaios randomizados controlados e 3 grupos de ensaios randomizados controlados com 3.634 participantes no total. Os autores concluíram que apesar de haver evidências de que os serious games e gamificação são pelo menos eficazes quanto as condições controles, alguns estudos apontam até serem mais eficazes ao aumentarem o conhecimento, melhorarem habilidades e a satisfação, entretanto, os estudos são de baixo rigor metodológico levando a evidência de baixa qualidade com alto nível de heterogeneidade tanto da população estudada quanto dos resultados. São estratégias com reais potenciais de melhora para o aprendizado e performance em profissionais da saúde. Contudo, futuros estudos com metodologias mais robustas e rigorosas, com voluntários de países 
de baixa renda, acessando resultados com pacientes, comportamento do participante, eventos adversos, entre outros são fundamentais para aprofundar o conhecimento das reais contribuições destas metodologias de aprendizado (GENTRY et al., 2019).

McCoy, Lewis e Dalton (2016) realizaram um levantamento de games eletrônicos, aplicativos de celulares e simulação de pacientes virtuais em estudos que utilizavam tais metodologias para o aprendizado e desenvolvimento de habilidades e treinamento adequado para educação médica geral pré-clínica e clínica. Como resultado, os autores observaram que os diferentes métodos (games eletrônicos, aplicativos de celulares e simulação de pacientes virtuais) tem o potencial de aumentar o engajamento, permite treinamento à distância, gera feedback rápido, aprimora colaboração, tem potência de aplicação no mundo real, permite treinamento de decisão clínica e análise da aprendizagem. Também encontraram 5 plataformas de treinamento pré-clínico (3D Anatomy, Bravo, Fold It, TurningPoint e Quizlet) e 4 aplicativos de celulares com o mesmo objetivo (Doctor's Dilemma, DO OMT, Neuroanatomy: Draw It to Know It, Socrative). Para o treinamento clínico encontraram 5 games eletrônicos (Dapper, ElderQuest, Image Challenge, Second Life, Septris), 10 aplicativos para celulares (3M Littmann Sound Builder, 12-Lead ECG Limmer, CathSource, Clinical Sense, drawMD, Essential Anatomy 5, Heart Pro III, Prognosis: Your Diagnosis, Radiology 2.0: One night in scans e Upper Respiratory Virtual Lab) e 12 simuladores de pacientes (3DiTeams, At-Risk in Primary Care, CliniSpace, DecisionSim, CLIPP, HumanSim, i-Human, MedU, Open Labyrinth, QuantiaMD, SimCoach, VPSim). Com relação aos games desenvolvidos ou implementados em estudos pilotos encontraram 9 plataformas de gamificação de artigos entre 2008 até 2015 (Burn Center, Casebook, The Virtual First Responder, CliniSpace, EMedOffice, Heart Murmur Sim, Nuclear Event Triage Challenge Pulse e TheraSim). Nos artigos os autores fizeram tabelas relacionando as habilidades treinadas, descrição e formas de acesso de cada um deles (MCCOY; LEWIS; DALTON, 2016).
Gorbanev e colaboradores (2018) realizaram um estudo de revisão sistemática do uso de serious games no Ensino Superior em Medicina, verificando qualidade das evidências e a estratégia pedagógica utilizada. Encontraram 494 artigos na área, contudo, apenas 21 artigos preencheram os critérios de inclusão. Dentre estes artigos, observaram que apenas 9 artigos utilizaram como metodologia ensaio controle randomizado, 16 tiveram como objetivo avaliar conhecimento e habilidades, e 5 analisaram percepção, atitude, satisfação, opinião e fatos gerais sobre o uso de games. Com relação ao público alvo nos estudos, 61,9\% eram universitários e $28 \%$ eram residentes. Com relação à estratégia pedagógica utilizada, 65\% dos games forma desenvolvidos para serem utilizados em sala de aula, 71,4\% foi desenvolvido para ser utilizado como estratégia complementar as aulas tradicionais, os outros foram utilizados como o centro da estratégia pedagógica. Já em relação ao tipo de estratégia pedagógica, $76,2 \%$ dos games foram classificadas como comportamentais ou cognitivistas, ou seja, focando em mudança de comportamento ou habilidades cognitivas como memória. Os resultados apontam para efeitos positivos no uso de games no processo de aprendizado, entretanto, os autores apontam que as qualidades das evidências encontradas foram moderadas (GORBANEV et al., 2018).

\section{Games, Serious Games e Gamificação em Outras Áreas}

Begosso e colaboradores (2018) investigaram - uso de gamificação na plataforma Moodle e uso de games para ensinar estudantes do curso de Ciências da Computação do primeiro ano conceitos da disciplina de Algoritmo. Participaram 44 estudantes da Faculdade de Tecnologia de Assis, que forma divididos em dois grupos: 22 no Grupo Game e 22 no Grupo Teste. Os participantes do Grupo Game receberam a intervenção de gamificação e games ao longo da disciplina e o Grupo Teste recebeu as aulas tradicionais com o mesmo conteúdo do Grupo Game. Como resultado, os autores observaram 
que o Grupo Game obteve notas maiores do que o grupo controle $(8.0 \pm 2.07$ vs $5.5 \pm 3.26, p<0,05)$ aumentando a motivação para aprender e a retenção do conteúdo. Além disso, 76,5 \% dos estudantes consideraram que as ferramentas disponibilizadas contribuíram para a aprendizagem de conceitos básicos de programação e $82,4 \%$ preferem aprender com a combinação de aulas tradicionais com games e gamificação. Os autores concluem que o uso de gamificação tem um papel importante na aprendizagem de conceitos de programação e algoritmos para os alunos de primeiro ano (BEGOSSO et al., 2018).

Visando o ensino de conhecimentos básicos e treinamento de habilidades de engenharia mecânica Galup, Segonds e Lagarrigue (2015), desenvolveram um serious game para ser utilizado antes das aulas práticas, o Mecagenius ${ }^{\circledR}$. $\bigcirc$ game foi desenvolvido pelo Instituto Nacional Universitaire Champollion em parceria com mais quarto instituições: KTM advance, Clément Ader Institute (Laboratório de Engenharia Mecânica, Universidade de Toulouse), L'Institut de Recherche en Informatique de Toulouse (Laboratório de Informática), L'Unité Mixte de Recherche 'Education Formation Travail et Savoir' (Laboratório de Didática) e Ecole de Technologie Supérieure de Montréal. O projeto foi financiado pelo governo Francês, em parte pelo Ministério da Economia, Indústria e Emprego Francês no âmbito da Chamada para Projetos Sérios (Secretaria de Estado da Economia Digital, 2009). Os autores testaram em um grupo de estudantes de engenharia mecânica e com os professores o uso do Mecagenius (Figura 12) e observaram que, apesar não ter interferido no desempenho final, verificaram que os estudantes com maior dificuldade passaram mas tempo no game fora do horário de aula, o que aprece ter contribuído para redução de nível entre os estudantes. Também observaram que o game contribuiu para a aprendizagem efetiva para a maioria dos estudantes, permitindo que dedicassem ao que mais precisavam devido à flexibilidade e liberdade que o game permite. A maioria dos alunos gostaram do game e desejavam continuar utilizando-o. Contudo, apontam para a necessidade de desenvolver estratégias específicas para os estudantes com maior dificuldade para ser mais efetivo e na necessidade de melhorar a avaliação e o progresso dos estudantes (GALUP; SEGONDS; LAGARRIGUE, 2015).

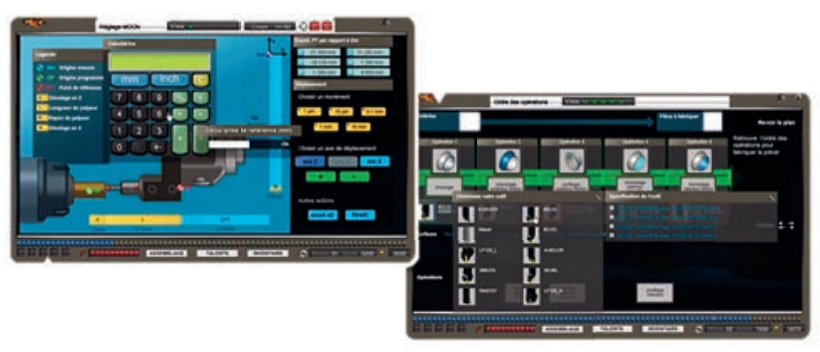

Figura 13 - Ilustração

das telas do Mecagenius

Fonte: Mecagenius

Triviño-Cabrera e colaboradores (2017), transformaram em gamificação o processo de aprendizagem sobre carregamento por wireless de Veículos Elétricos para estudantes do curso de Engenharia Industrial do segundo ano, na disciplina de Fundamentos da Engenharia Elétrica, na Universidade de Málaga, Espanha. Participaram 286 estudantes com idade entre 19 a 25 anos que foram divididos em quatro grupos. $O$ jogo recebeu o nome de Tesla e foi dividido em fases que correspondiam a níveis de conhecimento (Básica - fonte da voltagem, indutores e baterias; Médio - Elementos reativos para compensação de potência reativa; Avançado - Diodos; Expert - Conversores de energia). Os alunos respondiam questões conceituais ou pequenos problemas semanalmente relacionados a cada aula. Essas atividades foram chamadas de exercícios de Tesla.

Foram realizados 10 exercícios no total. Os acertos eram pontuados e o rank dos alunos era apresentado para aumentar competitividade. Os autores observaram que a gamificação é uma ferramenta útil, que aumentou a motivação dos alunos, mas houve um decréscimo desta motivação, apesar dos estudantes desejarem melhorar seu desempenho no jogo. Um ponto importante apontado pelos autores é a forma 
de pontuação que aumentou a competitividade e dificultou pontuações altas em grupos com número grande alunos, o que pode ter contribuído para a decréscimo da motivação. Apesar do jogo precisar de alguns ajustes, a percepção dos alunos foi positiva, permitiu que conceitos técnicos fossem mais acessíveis, aumentou a motivação extrínseca e melhorou as notas finais (TRIVIÑO-CABRERA et al., 2017).

Em outro estudo, Puzt e colaboradores (2018) utilizaram gamificação para a facilitação da aprendizagem e retenção de conhecimento em um workshop de um dia inteiro para 334 estudantes de logística em escolas profissionais na Áustria, no segundo ano e compararam os grupos que realizaram o workhop gamificado e o não gamificado. Os autores mediram em três momentos a intervenção: imediatamente, 20 minutos após e duas semanas após o workshop. O objetivo do worshop foi de treinar os estudantes de logística em transporte sustentável. Os 261 estudantes participaram do grupo gamificado (competição, pontuação nas atividades do workshop) e 73 participaram do não gamificado. Em relação aos resultados, observaram que melhor desempenho do grupo gamificado e manteve o conhecimento maior, memorizaram mais o conteúdo após duas semanas em relação ao grupo do workshop não gamificado (Workshop Gamificado Medida 1-3 Z = -9.127, $p<0,01 ;$ Workshop não gamificado Medida $1-3 Z=-3.498, p<0,01)$. A conclusão dos autores é de que a gamificação facilitou a retenção do conhecimento, apesar de uma queda após duas semanas, os alunos ainda lembravam mais do que o grupo que realizou o workshop não gamificado. Contudo, é importante ressaltar que o tamanho da amostra dos grupos é muito diferente e pode ter interferido na diferença de desempenho.

Em relação ao uso de games comerciais e desenvolvimento de habilidades importantes para os estudantes, Barr (2017) investigou o uso de games comerciais em alunos do curso de Artes e Humanidades na Universidade de Glasgow, Escócia, no desenvolvimento das habilidades: comunicação eficaz, adaptabilidade e desenvoltura. Os games utilizados foram Borderlands 2, Minecraft, Valve's Portal 2, Lara Croft and the Guardian of Light, Warcraft III: Reign of Chaos, Team Fortress 2, Gone Home e Papers, Please. Participaram 36 estudantes no grupo controle e 36 no grupo de intervenção. O grupo de intervenção jogou durante 8 semanas por 14 horas distribuídas pelos alunos, com recomendação de 60 minutos em cada game. Por meio de escalas o autor observou que os games comerciais melhoraram as habilidades de comunicação, adaptabilidade e desenvoltura em relação ao grupo controle em um curto período de tempo.

$\mathrm{Na}$ área de negócios, Lainema, Lainema e Islam (2018), realizaram um experimento para verificar o uso de Bussiness Simulation Game na aprendizagem prática (como fazer). Neste estudo utilizaram o Real Game, um game de simulação de processos de negócios em grupos pequenos (três pessoas) em que podem acompanhar as operações, fluxos e materiais da empesa em tempo real. O desempenho é medido pelo sucesso das tomadas de decisões do grupo por meio do fluxo de caixa, lucros, custos de produção, níveis de estoque e participação de mercado. Participaram do estudo 474 estudantes de Sistema de Gerenciamento de Informação em dois dias, com 27 sessões de treinamento no game Real Game que simula uma indústria líder que oferece soluções técnicas e equipamentos para diversos setores no mundo. Os autores observaram que a percepção dos participantes sobre o tipo de aprendizagem por meio do game é subjetiva e variou entre os participantes. A maior porcentagem pontuou similarmente que a simulação proporcionou aprendizagem do tipo de princípios gerais do assunto simulado e do tipo entendendo a estrutura do mundo real de maneira simplificada (29,2\% e 19,7\% respectivamente). Apenas 2,9\% pontuou o tipo de aprendizagem de referente a conceitos explícitos e 8,6\% para aprendizagem de colaboração e trabalho em equipe. Os autores pontuam a importância de estudos mais aprofundados uma vez que a percepcão do usuário nem sempre corresponde ao que 
os games de simulação propõem (LAINEMA, LAINEMA e ISLAM, 2018).

Business games também tem sido utilizado no treinamento de liderança. Lopes e colaboradores (2013) fizeram uma revisão sistemática de business games e seus objetivos, suas características técnicas e pedagógicas, a relação destes jogos com as teorias de liderança, bem como a eficácia destes no desenvolvimento de habilidades de liderança. Como resultado apenas 5 games estavam de acordo com os critérios (Administrator Case Simulation, Group Decision Simulation (A)-(F), LEADER, Army Excellence in Leadership e Virtual Leader). Além disso, os autores apontam a falta de estudos na área, que existe falta de relação entre as teorias sobre liderança e os businesses games, e sugerem estudos que verifiquem e validem os modelos dos games para mostrarem evidências de suas teorias de base. Outro ponto importante é que a experiência dos businesses games não garantem efetividade dos resultados da aprendizagem. Dessa forma, Lopes e colaboradores (2013), sugerem novos estudos com métodos de avaliação e feedback mais consistentes.

\section{Considerações Sobre o Uso de Games e Gamificação na Educação}

Apesar da literatura apontar para efeitos positivos e satisfatórios, Gorbanov e colaboradores (2018), apontam para a dificuldade em estabelecer o tamanho do efeito do objetivo pedagógico no uso de games e gamificação em estudantes de medicina devido às diferentes formas de medidas utilizadas pelos autores, uso de instrumentos não padronizados e a diversidade de áreas do saber dentro da medicina focada pelos autores. Outro fator limitante levantado pelos autores é a dificuldade de verificar a eficácia entre games, uma vez que os autores realizam um único estudo com o game e não realizam estudos comparativos, o que reduz a qualidade dos estudos. Mas não apenas na medicina, em outras áreas a mesma dificuldade é encontrada (DICHEVA et al., 2015).

No Ensino Superior os cursos de Ciências da Computação e Tecnologia da Informação (TI) são os que mais tem adotado o uso da gamificação em relação aos outros cursos. A falta de apoio tecnológico pode ajudar a explicar a falta do uso de gamificação nos cursos de outras áreas (DICHEVA et al., 2015). Futuros estudos podem explorar os motivos do baixo uso de games, serious games e gamificação nas outras áreas e até investigar a contribuição dos games, serious games e gamificação como no ensino da matemática, linguagem, artes, entre outros. Segundo Dichev e Dicheva (2017), o contexto educacional que o uso da gamificação pode ser particularmente benéfico ainda não está bem consolidada cientificamente. Além disso, saber o momento certo e a melhor forma de utilizar games, serious games ou gamificação pode ampliar os benefícios na aprendizagem (MORRIS et al., 2013). Futuros estudos precisarão debruçar sobre este aspecto importante para maximizar os benefícios.

Na Educação Básica os mesmos desafios são enfrentados como os apontados acima. Os estudos têm trazido benefícios para os seus estudantes, mas a forma de avaliar os efeitos na aprendizagem ainda são frágeis e sem os devidos controles de variáveis que podem interferir nos resultados. É comum esperarmos que as crianças e jovens gostem dos games, mas o uso destes com o intuito de aprender e estimular habilidades cognitivas, apresentam dificuldades de expressar através de resultados quantitativos estes resultados (KAAP, 2012; LIMA, 2017).

\section{Conclusão}

O presente estudo teve como objetivo apresentar sobre o uso de games, serious games e gamificação na educação básica e no Ensino Superior, bem como as evidências científicas do uso combinado de estratégias pedagógicas tradicionais com games, serious games e gamificação na efetividade da aprendizagem e desenvolvimento de habilidades. Alguns games, serious games e estratégias de gamificação foram 
apresentados de forma a dar um panorama do que se tem feito em âmbito nacional e internacional. Foi possível mostrar a diversidade de games, serious games e estratégias já sendo implementados como parte da grade de curso de medicina, bem como games em fase inicial de desenvolvimento, mas com promissora contribuição ao processo de aprendizagem e desenvolvimento de habilidades. Contudo, apesar de se mostrarem ferramentas interessantes no aprendizado e desenvolvimento de habilidades, falta replicação de estudos com metodologias mais rigorosas como ensaios controlados randomizados com instrumentos e medidas mais precisos para garantir que tipo de conhecimento e habilidade os games estão de fato desenvolvendo, antes de serem efetivamente implementados na educação básica e nos cursos de Ensino Superior.

Outro ponto importante é a discrepância entre a quantidade de estudos e games para as diferentes áreas do Ensino Superior e para o Ensino Básico. Alguns cursos ainda têm poucos games, serious games e gamificação sendo desenvolvidos ou estudados, bem como falta desenvolvimento destas estratégias para a educação básica. Apesar da estratégia da gamificação ter se mostrado interessante e motivadora para os alunos, ainda faltam estudos que tragam evidências científicas rigorosas e robustas que apontem quais estratégias são mais efetivas. Além disso, algumas variáveis dificultam a compreensão da efetividade destas estratégias como o tempo disponível entre as aulas tradicionais e o uso de games, a acessibilidades, recursos das instituições de ensino como acesso a internet ou computadores, conhecimento e habilidade dos professores para desenvolverem e aplicarem games e gamificacão em suas aulas. Futuros estudos precisarão ser realizados para verificar se algum game ou serious game poderá substituir alguma forma tradicional de ensino. Outro ponto importante a ser estudado é a dificuldade de estabelecer a relação de desenvolvimento de habilidades em outros contextos por meio dos games comerciais. Medidas mais precisas e forma de uso destes games precisará ser verificado, bem como uso de aplicativos comerciais.
Em suma, o avanço tecnológico e o interesse das instituições de ensino em aumentar a motivação e obter formas mais eficazes no desenvolvimento de habilidades e aprendizagem de conceitos aplicados a prática tem crescido nos últimos anos e o uso de novas tecnologias como a realidade virtual e inteligência artificial tem contribuído para tais objetivos. Já existem no mercado games interessantes, alguns apresentados no presente panorama, que tendem aperfeiçoarem ainda mais com o uso ampliado e serem mais utilizados como estratégia complementar as tradicionais estratégias de ensino e aprendizagem.

\section{Referências}

ALMEIDA, F.; SIMOES, J. The Role of Serious Games, Gamification and Industry 4.0 Tools in the Education 4.0 Paradigm. Contemporary Educational Technology, v. 10, n. 2, p. 120-136, 2019. ARAÚJO, W. O.; SILVA, R. da; ARANHA, E. H. S. Aplicação de Jogos Adaptativos na Educação: uma Revisão Sistemática da Literatura. In: CONGRESSO BRASILEIRO DE INFORMÁTICA NA EDUCAÇÃO (CBIE), 5., 2016; SIMPÓSIO BRASILEIRO DE INFORMÁTICA NA EDUCAÇÃO (SBIE), 27., 2016. Anais... 2016. p. 587-596.

BARR, M. Video games can develop graduate skills in higher education students: A randomised trial. Computers \& Education, v. 113, p. 86-97, 2017.

BEDWELL, W. L. et al. Toward a taxonomy linking game attributes to learning: An empirical study. Simulation \& Gaming, v. 43, n. 6, p. 729-760, 2012.

BEGOSSO, L. R. et al. The Use of Gamification for Teaching Algorithms. Communication Papers of the Federated Conference on Computer Science and Information Systems, v. 17, pp. 225-231, 2018.

BIGDELI, S.; KAUFMAN, D. Digital games in health professions education: Advantages, disadvantages, and game engagement factors.

Medical Journal of the Islamic Republic of Iran, v. 31, p. 117, 2017. 
CODISH, D.; RAVID, G. Detecting playfulness in educational gamification through behavior patterns. IBM Journal of Research and Development, v. 59, n. 6, p. 6: 1-6: 14, 2015.

CHIN LU, C.; JENG, S.-L. Developing Digital Game Based on the Conception of Insect (DGBI) to Test Elementary Student's Insect Conceptions. Creative Education, v. 3, n. 8b, p. 101-110, 2013.

CHON, S.-H. et al. Serious Games in Surgical Medical Education: A Virtual Emergency Department as a Tool for Teaching Clinical Reasoning to Medical Students. JMIR Serious Games, n.7, v. 1, p. e13028, 2019.

CSIKSZENTMIHALYI, M. Flow: The psychology of optimal performance. New York: Cambridge University Press, 1990.

GARRIS, R.; AHLERS, R.; DRISKELL, J. E. Games, motivation, and learning: A research and practice model. Simulation \& gaming, v. 33, n. 4, p. 441-467, 2002.

DELAVALLI, C.; CORRÊA, M. M. C. Informática na Educação: uso de aplicativos para estímulo do estudo em rede. Trabalho de conclusão de curso. Escola de Informática Aplicada. Universidade Federal do Estado do Rio de Janeiro. Rio de Janeiro, 2014.

DICHEV, C.; DICHEVA, D. Gamifying education: what is known, what is believed and what remains uncertain: a critical review. International Journal of Educational Technology in Higher Education, v. 14, n. 1, p. 9, 2017.

DETERDING, S. et al. From game design elements to gamefulness: defining gamification. New York, NY: ACM. 2011.

DI DOMENICO, S. I.; RYAN, R. M. The emerging neuroscience of intrinsic motivation: a new frontier in self-determination research. Frontiers in Human Neuroscience, v. 11, p. 145, 2017.

GALAUP, M. et al. Mecagenius: An Innovative Learning Game for Mechanical Engineering. International Journal of Engineering Education, v. 31, n. 3, p.786-797, 2015.

GEE, J. P. What video games must teach us about learning and literacy. Palgrave Macmillan, 2003.
GENETIC Science Learning Center, Universidade de Utha. Learn. Genetics, 2018. Disponivel em:<https://learn.genetics.utah.edu/>. Acesso em: 22 de junho de 2019.

GORBANEV, I. et al. A systematic review of serious games in medical education: quality of evidence and pedagogical strategy. Medical Education Online, v. 23, n. 1, p. 1438718, 2018.

HUNG, A. C. Y. et al. Gamification in the wild: Faculty perspectives on gamifying learning in higher education. Issues and Trends in Educational Technology, v. 5, n. 2, 2017.

HUIZINGA, J. Homo Ludens: o jogo como elemento da cultura. Tradução: João Paulo Monteiro. São Paulo: Perspectiva, 2001.

HWANG, G.-J.; CHIU, L.-Y;; CHEN, C.-H. A contextual game-based learning approach to improving students' inquiry-based learning performance in social studies courses. Computers \& Education, v. 81, p. $13-25,2015$.

KAPP, K. M. The gamification of learning and instruction: Game-based methods and strategies for training and education. San Francisco: Pfeiffer, 2012.

LAINEMA, T.; ISLAM, A. K. M.; LAINEMA, K. Assessing the Potential Learning from Simulation Games. In: Twenty-fourth americas Conference on Information Systems, New Orleans, 2018.

LEE, H.; DOH, Y. Y. A Study on the relationship between educational achievement and emotional engagement in a gameful interface for video lecture systems. International Symposium on Ubiquitous Virtual Reality, p. 34-37, 2012.

LIMA, L. L. P. de. Aplicativo Educacional para inserção da lógica computacional para crianças. Trabalho de conclusão de curso. Ciência da Computação. Universidade de Caxias do Sul. Caxias do Sul, 2017.

LOPES, M. C. et al. Business games for leadership development: A systematic review. Simulation \& Gaming, v. 44, n. 4, p. 523-543, 2013.

MARTINS, C.; GIRAFFA, L. M. M. Gamificação nas práticas pedagógicas: teorias, modelo 
e vivências. Nuevas Ideas en Informática Educativa TISE: São Paulo, p. 42-53, 2015.

MIDDEKE, A. et al. Training of clinical reasoning with a Serious Game versus small-group problem-based learning: A prospective study. PloS one, v. 13, n. 9, p. e0203851, 2018.

MCCOY, L.; LEWIS, J. H.; DALTON, D. Gamification and multimedia for medical education: a landscape review. J. Am. Osteopath Assoc., v. 116, n. 1, p. 22-34, 2016.

MORRIS, B. et al. Gaming science: the "Gamification" of scientific thinking. Frontiers in Psychology, v. 4, p. 607, 2013.

NETO, A. N.; SILVA, A. P.; BITTENCOUR, I. I. Uma análise do impacto da utilização de técnicas de gamificação como estratégia didática no aprendizado dos alunos. In: SIMPÓSIO BRASILEIRO DE INFORMÁTICA NA EDUCAÇÃO, 26., 2015, Alagoas. Anais... 2015. p. 667-676.

OLIVEIRA, D. Proposta de um aplicativo personalizável para auxiliar no processo de alfabetização baseado no jogo da forca. Trabalho de Conclusão de Curso. Ciência da Computação. Universidade Federal da Paraíba (UFPB). Paraíba, 2017.

OLIVEIRA, T. de et al. Ensino de Raciocínio Lógico e Computação para crianças: Experiências, Desafios e Possibilidades. In: CONGRESSO DA SOCIEDADE BRASILEIRA DE COMPUTAÇÃO, 37., 2017, São Paulo. Anais... 2017. p. 2.090-2.099.

PANTOJA, A. da S.; PEREIRA, L. M. Estudo de caso: uma escola pública do Estado do Amapá: Macapá. Revista, v. 8, n. 1, p. 111-120, jan./abr. 2018.
PUTZ, L.-M. et al. The influence of gamified workshops on students' knowledge retention. In: INTERNATIONAL GAMIFIN CONFERENCE, 2., 2018, Tampere, Finland. 2018.

ROBINSON, K.; ARONICA, L. Escolas criativas - a revolução que está transformando a educação. Porto Alegre, RS: Penso, 2019.

SAILER, M. et al. How gamification motivates: An experimental study of the effects of specific game design elements on psychological need satisfaction. Computers in Human Behavior, v. 69, p. 371-380, 2017.

SANTOS, J. de Á. dos; FREITAS, A. L. C. de. Gamificação Aplicada a Educação: Um Mapeamento Sistemático da Literatura. Rev. Novas Tecnologias na Educação, Rio Grande do Sul, v. 15, n. 1, jul. 2017.

TORRES, H. da G. et al. O que pensam os jovens de baixa renda sobre a escola. Projeto de pesquisa desenvolvido pelo CEBRAP com o apoio da Fundação Victor Civita. Ministério da Educação, 2013.

TRIVIÑO CABRERA, A. et al. Tesla: a gamification framework to motivate students in Industrial Engineering. 2017.

VAN ECK, R. Digital game-based learning: it's not just the digital native who are restless. Educause Review, vol. 41, p. 16-30, 2006.

WATSON, J. M.; STRAYER, D. L. Supertaskers: Profiles in extraordinary multitasking ability. Psychonomic Bulletin \& Review, v. 17, n. 4, p. 479485, 2010.00.Fonte: <https://learn.genetics.utah. edu/content/addiction/mouse $>$. 